\title{
Volume 9, Number 3
}

Fall 2014

\section{Contents}

\section{Feature Articles \\ Interdependence: Ninth and Newest Critical Element for 4-H Positive Youth Development \\ [Article 140903FA001]} Page 4 Astroth, Kirk A.

For the past 15 years, a list of eight critical elements has provided a strong foundation for articulating the positive youth development focus of $4-\mathrm{H}$ programs and efforts. Now it is time to revisit this list and update the critical elements for positive youth development. Interdependence is proposed as a $9^{\text {th }}$ critical element that should be included. Research is cited for the importance of this element that was not included in the original list in 1998, and a call is made for a national think tank to update the critical elements.

\section{Life Skill Influence of Consumer Decision Making Program: Intensity and Breadth}

[Article 140903FA002] Page 13

Olson, Carrie Ann; Croymans, Sara R.; Ji, Kangting

The study presented in this paper focuses on an important aspect of life-event decision making: Consumer Decision Making. The purpose of the reported research was to ascertain if there is correlation between participating in the 4-H Consumer Decision Making (CDM) Program and life skill development. The study identified twelve life skills. The research hypothesis was that participants involved in multiple opportunities of the CDM program will report higher levels of positive life skill development than individuals reporting minimal involvement. Participants reported the 4-H CDM Program influenced development of decision making, critical thinking, and useful/ marketable life skills. The study investigated the relationship between member participation in eight core CDM program opportunities in Minnesota 4-H and life skill development. The study found that county fair project exhibit, county day camp, state consumer decision making educational activity/field trip, and consumer decision making judging contests have significant influence on life skills. It was determined that participants involved in more opportunities (6-8) reported greater influence on life skill development than participants in only 1-2 program opportunities.

The Career Maturity of 4-H Healthy Lifestyles Program Participants [Article 140903FA003] Page 28 Dodd, Courtney F.; Odom, Summer F.; Boleman, Christopher T.

This study examined the readiness of youth involved in the 4-H healthy lifestyles program to make career decisions, identified as career maturity. A random sample of youth involved in the 4-H healthy lifestyles program was used to participate in the research study, which entailed the completion of an online survey. The findings indicate that youth in the 4- $\mathrm{H}$ healthy lifestyles 
program have a high level of career maturity with some significant differences found based upon age; however, no significant differences were found based upon gender or years of involvement in the 4-H program.

\section{Addressing the Issue: Bullying and LGBTQ Youth}

[Article 140903FA004]

Page 40

Allen, Kimberly

Each day, thousands of youth experience bullying and as many of $70 \%$ of all youth report having experienced bullying, either directly or indirectly (Cantor, 2005). For Gay, Lesbian, Bi-sexual, Transgender and Questioning (LGBTQ) youth, the chances of experiencing bullying are much higher than for youth in the general population (Russell, Horn, Kosciw, \& Saewyc, 2010). Although many youth serving organizations have begun to address the issue of bullying with bullying prevention programs, there is a deficit of information and a lack of inclusion of prevention efforts that specifically address LGBTQ youth. This article address the role of youth organizations in creating safe and inclusive environments for all youth, with specific attention paid to resources and strategies for inclusive environments for LGBTQ youth.

\section{Program Articles}

Intergenerational Service Learning Program Improves Aging Knowledge and Expectations and Reduces Ageism in Younger Adults

[Article 140903PA001]

Page 47

Francis, Sarah L.; Margrett, Jennifer A.; Hoerr, Kara; Peterson, Marc J.; Scott, Abbie;

Franke, Warren D.

This article discusses a study which evaluated the effects of an intergenerational service-learning exergaming program for older adults on younger adults' aging knowledge, expectations, and perceptions. Eighteen college students (ages 19-26 years) served as trainers for an 8-week exergaming physical activity program for older adults (12 contact hours). Questionnaires assessing aging knowledge, ageist attitudes and aging expectations were completed at Weeks 1 , 8 , and 25 (follow-up); program evaluations were completed at Weeks 8 and 25. Significant improvement from Week 1 to Week 25 was found for: Aging knowledge scores $(p<0.03)$, positive aging expectations regarding mental health $(p<.02)$, positive aging expectations regarding cognitive health $(p=.043)$, overall aging expectations $(p<.05)$, ageism (stereotypes) $(p<.02)$ and ageism (separation) $(p=.000)$. All trainers ranked their experience as "good to excellent." This intergenerational service learning program is effective in improving aging knowledge, expectations and perceptions.

\section{Effective, Efficient Online Training in Cooperative Extension}

[Article 140903PA002] Page 58

Young, Jane Chin; Manton, Linda Marie; Worker, Steven M.; Martin, Anna C.

In order to keep pace with media and communications trends in education, Cooperative Extension (CE) faces the need to shift from traditional face-to-face delivery to online alternatives. This exploratory study focused on evaluating the effectiveness of on-demand, interactive online training compared to its face-to-face counterpart. Targeted for CE staff and volunteers whose work impacts youth, families and communities, the design centered on the university's cost-effective in-house technology tools. The study results make the case for online delivery as effective and efficient. Strategies for developing a process for online delivery in CE are also offered. 


\section{4-H and 4-H Members in Motion Pictures}

[Article 140903PA003]

Page 66

Scholl, Jan

Youth involved in Extension activities were portrayed on film as early as 1913. This paper provides a summary of the earliest motion pictures in which $4-\mathrm{H}$ and $4-\mathrm{H}$ members were a part. From the more than 400 early Extension films made by USDA, 22 4- $\mathrm{H}$ films were located and described. Hollywood films, with 4-H themes, were found. Reflections on film preservation and availability are addressed as well as the role of film and other media in the early twentieth century.

\section{Resource Review}

\section{A Collaborative Effort to Address Adolescent Obesity in Primary Care}

[Article 140903RR001] Page 79

Bernetich, Meghan; Patterson, Jennifer $A$.

Adolescent obesity is a growing national healthcare concern. Barriers to effective treatment, such as limited time for office visits and limited reimbursement for obesity counseling, leave both patient and practitioner feeling frustrated and unsupported. This article will discuss the adolescent weight management program, Triple E: Eat, Exercise, and Enjoy. This program was created in collaboration with a pediatric primary care practice, a local university, an affiliated pediatric practice within the health system, the local middle school, and the community. Triple $E$ was developed, with minimal funding, to combat the adolescent obesity epidemic occurring in a primary care practice.

\section{Resource Review: The State of Girls: Unfinished Business}

[Article 140903RR002] Page 84

\section{Dawson, Patricia}

The State of Girls: Unfinished Business is an extensive report published by the Girl Scout Research Institute. The 156 page publication examines girls' health and well-being in the United States with a focus on key issues including health, educational achievement, demographic trends and safety. The report includes excellent charts, tables and diagrams and an appendix of state-level sources of data to support research findings. Youth professionals will appreciate this well documented, easy to comprehend resource as they engage in positive youth development programming. 